$06.3 ; 07.2 ; 07.3$

\title{
Замена туннельных переходов в InP на каналы проводимости с кристаллитами GaP
}

\author{
() А.Е. Маричев, В.С. Эполетов, А.С. Власов, Б.В. Пушный, А.И. Лихачев, А.В. Нащекин \\ Физико-технический институт им. А.Ф. Иоффре РАН, Санкт-Петербург, Россия \\ E-mail: aemarichev@mail.ioffe.ru
}

Поступило в Редакцию 1 июня 2021г.

В окончательной редакции 15 августа 2021 г.

Принято к публикации 18 августа 2021 г.

\begin{abstract}
Представлены результаты исследований методом тока, индуцированного электронным зондом, $p-n$-переходов на основе InP с кристаллитами GaP в области объемного заряда. Показано, что введение кристаллитов в область пространственного заряда приводит к закорачиванию $p-n$-перехода. Качество материала, выращенного поверх кристаллитов, позволяет создавать фотоактивные области, о чем свидетельствуют измерения спектров фотолюминесценции.
\end{abstract}

Ключевые слова: кристаллиты, туннельный переход, соединительный элемент.

DOI: 10.21883/PJTF.2021.22.51729.18893

В настоящее время наиболее эффективные солнечные фотоэлементы изготавливаются на основе каскадных гетероструктур. В таких приборах три или четыре фотоактивных $p-n$-перехода, работающих в разных спектральных диапазонах, соединяются последовательно туннельными переходами с предельно высокими уровнями легирования $[1,2]$. При достаточно высокой плотности излучения генерируемый фототок может превысить пиковый ток туннельных переходов, что ведет к увеличению сопротивления всей структуры и падению эффективности работы прибора [3].

В приборах на основе фосфида индия сложно получить качественные туннельные переходы из-за особенностей легирования фосфида индия примесями $p$-типа $[4,5]$. Возможным путем решения этих проблем является замена туннельных переходов на каналы проводимости, например получаемые посредством создания массива кристаллических включений в области объемного заряда (OO3) между соседними фотоактивными $p-n$-переходами [1]. В этом случае в каналах проводимости обеспечивается линейная зависимость протекающего тока. В работах [6,7] были впервые предложены и экспериментально исследованы $p-n$-переходы на основе $\mathrm{GaSb}$, в OO3 которых были введены кристаллиты кремния. Данное решение закреплено патентом РФ [8].

Для создания каналов проводимости нужно, чтобы материал кристаллитов в области объемного заряда удовлетворял следующим условиям: 1) необходимо наличие слабого поглощения оптического излучения; 2) материал кристаллитов не должен образовывать на границе $p-n$-переходов монокристаллический слой, а должны формироваться отдельные кристаллиты.

Важным является сохранение качества материала фотоактивных переходов, выращенных поверх слоев, содержащих нанокристаллиты, так как снижение их качества приводит к уменьшению эффективности преоб- разования излучения. Особенности получения массивов кристаллитов $\mathrm{GaP}$ на слое InP описаны в $[9,10]$.

В настоящей работе представлены результаты исследований вольт-амперных характеристик (BAX) и проводимости $p-n$-перехода на основе InP с кристаллитами $\mathrm{GaP}$, включенными в область объемного заряда, методом тока, индуцированного электронным зондом (ТИЭЗ). Метод ТИЭЗ позволяет анализировать электрические характеристики структур в объеме без создания омических контактов. Следует отметить, что низкоомные контакты к $p$-InP [11] сложно изготавливать, и это влияет на измерения вольт-амперных характеристик. Методом фотолюминесценции оценивалось качество InP, выращенного на слое с кристаллитами.

Структуры выращивались методом газофазной эпитаксии из металлоорганических соединений на установ-

\begin{tabular}{|c|}
\hline$p-\operatorname{InP}(\sim 1 \mu \mathrm{m}), p=5 \cdot 10^{18} \mathrm{~cm}^{-3}$ \\
\hline$n-\operatorname{InP}(\sim 1 \mu \mathrm{m}), n=5 \cdot 10^{18} \mathrm{~cm}^{-3}$ \\
\hline$n-\operatorname{InP}(100)$ \\
\hline
\end{tabular}

\begin{tabular}{|c|}
\hline$p-\operatorname{InP}(\sim 1 \mu \mathrm{m}), p=5 \cdot 10^{18} \mathrm{~cm}^{-3}$ \\
\hline $\operatorname{GaP}(\sim 0.08 \mu \mathrm{m})$ \\
\hline$n-\operatorname{InP}(\sim 1 \mu \mathrm{m}), n=5 \cdot 10^{18} \mathrm{~cm}^{-3}$ \\
\hline$n-\operatorname{InP}(100)$ \\
\hline
\end{tabular}

Рис. 1. Схематические изображения структур, выращенных на подложках $n$-InP. $a-p-n$-переход, $b-$ соединительный $p-n$-переход с кристаллитами $\mathrm{GaP}$ в ООЗ 

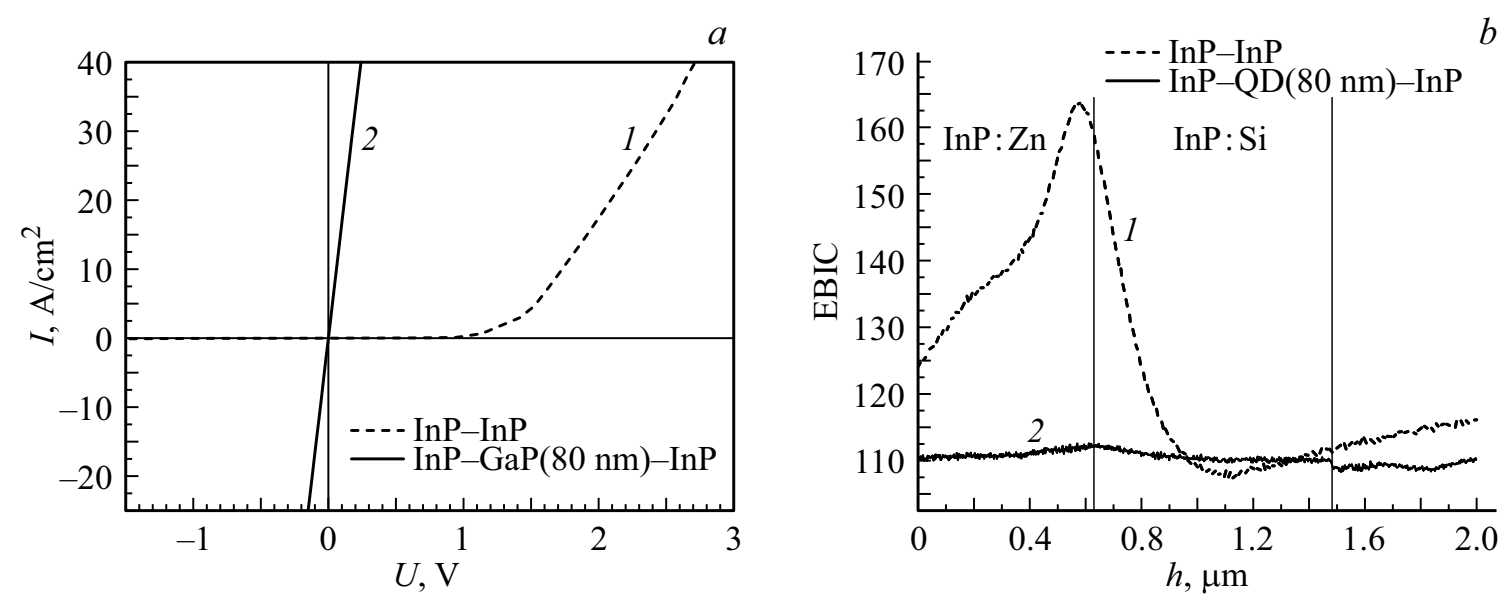

Рис. 2. $a-\mathrm{BAX}, b-$ сигнал ТИЭЗ структур на основе InP, выращенных на $n$-подложках. $1-p-n$-переход; $2-p-n$-переход с GaP-кристаллитами в ОО3.

ке AIX-200 (AIXTRON, Германия) [9] на подложках $n$-InP(100). В настоящей работе изготовлены два типа структур, представленные на рис. 1: 1) $p-n$-переход на основе InP, $n$ - и $p$-слои имели концентрацию $5 \cdot 10^{18} \mathrm{~cm}^{-3}$ и толщину $\left.1 \mu \mathrm{m}(a) ; 2\right) p-n$-переход на основе InP с кристаллитами $\mathrm{GaP}$, включенными в $\mathrm{OO}$, $n$ - и $p$-слои имели концентрацию $5 \cdot 10^{18} \mathrm{~cm}^{-3}$ и толщину $1 \mu \mathrm{m}$, а толщина кристаллитов была равна $80 \mathrm{~nm}(b)$.

Измерения ВАХ проводились при комнатной температуре в диапазоне плотностей тока от $10^{-8}$ до $40 \mathrm{~A} / \mathrm{cm}^{2}$, данные представлены на рис. $2, a$ ( кривая 1 соответствует ВАХ $p-n$-перехода без кристаллитов в ООЗ, кривая 2 отвечает $\mathrm{BAX} p-n$-перехода с кристаллитами, включенными в ООЗ, и имеет линейный характер).

Исследования методом ТИЭЗ проводились на растровом электронном микроскопе CAMSCAN Series 4-88 DV100 (Англия) с блоком усилителя „ЕВIC“ (ФТИ им. А.Ф. Иоффе, Россия) и энергией электронов $5 \mathrm{keV}$. На рис. $2, b$ представлен сигнал ТИЭЗ исследуемых структур: $p-n$-перехода без кристаллитов в ООЗ (кривая 1) и $p-n$-перехода с кристаллитами, включенными в ОО3 (кривая 2). Из зависимостей видно, что введение кристаллитов в ООЗ приводит к закорачиванию $p-n$-перехода.

Оценка качества материала верхнего слоя структуры, состоящей из эпитаксиального слоя $p$-InP толщиной $1 \mu \mathrm{m} \mathrm{c}$ концентрацией $5 \cdot 10^{18} \mathrm{~cm}^{-3}$, выращенного на слое кристаллитов $\mathrm{GaP}$ с размерами $80 \mathrm{~nm}$, проводилась методом фотолюминесценции в диапазоне длин волн 600-1500 nm при температуре жидкого азота $(77 \mathrm{~K})$. Для возбуждения люминесценции использовался $\mathrm{Nd}$ YAG-лазер с длиной волны излучения $532 \mathrm{~nm}$ и мощностью до $130 \mathrm{~mW}$. Плотность мощности возбуждения составляла $\sim 100 \mathrm{~W} / \mathrm{cm}^{2}$, в качестве детектора использовался PbS-фоторезистор.

На рис. 3 приведено сравнение спектров фотолюминесценции контрольного образца без промежуточного подслоя $\mathrm{GaP}$ (кривая 1) и исследуемого образца с

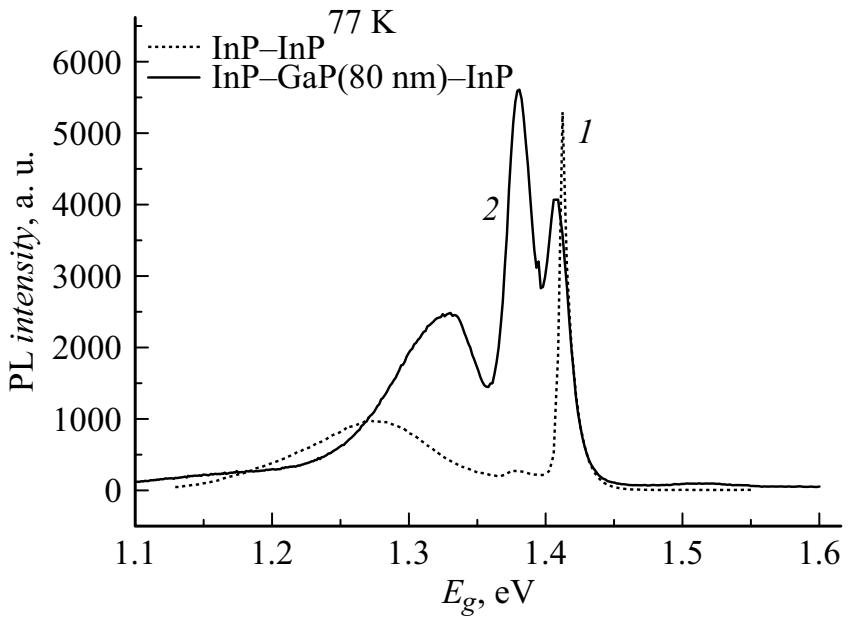

Рис. 3. Спектры фотолюминесценции контрольного образца $p-n$-перехода без кристаллитов $\mathrm{GaP}(1)$ и образца с кристаллитами $\mathrm{GaP}$ высотой $80 \mathrm{~nm}(2)$.

кристаллитами $\mathrm{GaP}$ высотой $80 \mathrm{~nm}$ (кривая 2). В спектре контрольного образца присутствуют три полосы: $1.41 \mathrm{eV}$ (межзонная рекомбинация), $1.38 \mathrm{eV}$ (переход с участием мелкого акцепторного уровня) и $1.28 \mathrm{eV}$ (полоса, которую обычно приписывают собственным антиструктурным дефектам замещения в InP [12]).

В спектре фотолюминесценции материала на кристаллитах $\mathrm{GaP}$ обнаруживаются изменения. Основная полоса $1.41 \mathrm{eV}$ уширяется и смещается в сторону более низких энергий, а интенсивность полосы $1.38 \mathrm{eV}$ растет. Такое поведение свидетельствует об увеличении концентрации дырок в верхнем слое InP, что согласуется с расчетами из первых принципов [13]. При этом важно отметить, что интенсивность фотолюминесценции не уменьшается. Это указывает на то, что введение кристаллитов GaP в промежуточный слой не приводит к появлению значимого количества центров безызлучательной рекомбинации, 
например дислокаций. Полоса $1.28 \mathrm{eV}$ при введении слоя кристаллитов $\mathrm{GaP}$ увеличивается по интенсивности и смещается в сторону более высоких энергий. Также появляется дополнительная полоса $1.33 \mathrm{eV}$.

Таким образом, показано, что метод ТИЭЗ позволяет выявлять особенности протекания тока через $p-n$-переход при введении кристаллитов $\mathrm{GaP}$ в ОО3 структуры. В том случае, когда размеры кристаллитов больше ширины ОО3, происходит закорачивание $p-n$-перехода, что подтверждено методом ТИЭЗ и исследованиями BAX. Качество материала, выращенного поверх кристаллитов, позволяет создавать фотоактивные области, о чем свидетельствуют результаты исследований фотолюминесценции.

\section{Благодарности}

Электронно-микроскопические и ТИЭЗ-исследования выполнены с использованием оборудования Федерального ЦКП „Материаловедение и диагностика в передовых технологиях“.

\section{Конфликт интересов}

Авторы заявляют, что у них нет конфликта интересов.

\section{Список литературы}

[1] Ж.И. Алфёров, В.М. Андреев, В.Д. Румянцев, ФТП, 38 (8), 937 (2004). [Zh.I. Alferov, V.M. Andreev, V.D. Rumyantsev, Semiconductors, 38 (8), 899 (2004).

DOI: $10.1134 / 1.1787110]$.

[2] N.H. Karam, R.A. Sherif, R.R. King, in Concentrator photovoltaics, ed by A.L. Luque, V. Andreev. Springer Ser. in Optical Sciences (Springer, Berlin-Heidelberg, 2007), vol. 130, p. 199-219. DOI: 10.1007/978-3-540-68798-6

[3] V.M. Andreev, E.A. Ionova, V.R. Larionov, V.D. Rumyantsev, M.Z. Shvarts, G. Glenn, in 2006 IEEE 4th World Conf. on photovoltaic energy conversion (IEEE, 2006), vol. 1, p. 799-802. DOI: 10.1109/WCPEC.2006.279577

[4] E.F. Schubert, C.J. Pinzone, M. Geva, Appl. Phys. Lett., 67 (5), 700 (1995).

[5] M.F. Vilela, A. Freundlich, A. Bensaoula, N. Medelci, P. Renaud, in Proc. of the 14th Space Photovoltaic Research and Technology Conf. (SPRAT 14) (NASA Lewis Research Center, Cleveland, OH, 1995), p. 11.

[6] V.M. Andreev, V.S. Kalinovsky, R.V. Levin, B.V. Pushniy, V.D. Rumyntsev, in Proc. of the 24th Eur. Photovoltaic Solar Energy Conf. (Hamburg, 2009), p. 740-742.

DOI: 10.4229/24thEUPVSEC2009-1DV.5.16

[7] В.С. Калиновский, Р.В. Лёвин, Б.В. Пушный, М.Н. Мизеров, В.Д. Румянцев, В.М. Андреев, ФТП, 47 (12), 1677 (2013). [V.S. Kalinovsky, R.V. Levin, B.V. Pushniy, M.N. Mizerov, V.D. Rumyantsev, V.M. Andreev, Semiconductors, 47 (12), 1652 (2013). DOI: $10.1134 / \mathrm{S} 1063782613120105]$.

[8] Полупроводниковая многопереходная структура, патент RU106443U1 (опубл. 10.07.2011).
[9] A.E. Marichev, B.V. Pushnyi, R.V. Levin, N.M. Lebedeva, N.D. Prasolov, E.V. Kontrosh, J. Phys.: Conf. Ser., 993, 012036 (2018). DOI: 10.1088/1742-6596/993/1/012036

[10] Р.В. Левин, А.Е. Маричев, Е.В. Контрош, Н.Д. Прасолов, В.С. Калиновский, Б.В. Пушный, Письма в ЖТФ, 44 (24), 25 (2018). DOI: 10.21883/PJTF.2018.24.47026.17458 [R.V. Levin, A.E. Marichev, E.V. Kontrosh, N.D. Prasolov, V.S. Kalinovskii, B.V. Pushnyi, Tech. Phys. Lett., 44 (12), 1130 (2018). DOI: 10.1134/S1063785018120490].

[11] В.С. Эполетов, А.Е. Маричев, Б.В. Пушный, Р.А. Салий, Письма в ЖТФ, 46 (23), 13 (2020). DOI: 10.21883/PJTF.2020.23.50340.18467 [V.S. Epoletov, A.E. Marichev, B.V. Pushnyi, R.A. Salii, Tech. Phys. Lett., 46 (12), 1167 (2020). DOI: 10.1134/S1063785020120056].

[12] Y. Zhao, Z. Dong, J. Appl. Phys., 100 (12), 123519 (2006). DOI: $10.1063 / 1.2404467$

[13] R. Mishra, O.D. Restrepo, A. Kumar, W. Windl, J. Mater. Sci., 47 (21), 7482 (2012). DOI: 10.1007/s10853-012-6595-8 